This is the author's version of a work that was submitted/accepted for publication in the following source:

Davey, C L, McDonald, J, Lowe, D, Duff, R, Powell, J A and Powell, J E (2006) Defects liability management by design. Building Research and Information, 34(2), 145-153, eScholarID:1a5083 | DOI:10.1080/09613210500492991

This file was downloaded from: https://www.escholar.manchester.ac.uk

(C) Copyright 2006 Taylor and Francis

Reproduced in accordance with the copyright policy of the publisher. Notice: Changes introduced as a result of publishing processes such as copyediting and formatting may not be reflected in this document. For a definitive version of this work, please refer to the published source. 


\title{
Defects Liability Management by Design
}

\section{Caroline L. Davey ${ }^{1}$, John McDonald ${ }^{2}$, David Lowe ${ }^{3}$, Roy Duff ${ }^{3}$, James. A. Powell ${ }^{4}$ and Jennifer. E. Powell ${ }^{5}$}

\author{
${ }^{1}$ Reader in Design, Innovation \& Society (correspondence author) \\ Design \& Innovation Research Group, University of Salford, \\ Centenary Building, Peru Street, Salford M3 6EQ, UK \\ Tel: +44 (0)1612953577 \\ Email: c.davey@salford.ac.uk
}

${ }^{2}$ Rowlinson Constructions Ltd, London House, London Road South, Poynton, Stockport, SK12 1YP, UK.

Email: john.mcdonald@rowcon.co.uk

${ }^{3}$ Management of Projects Research Group, School of Mechanical, Aerospace and Civil Engineering, University of Manchester, PO Box 88, Sackville Street, Manchester, M60 1QD, UK Email: david.lowe@manchester.ac.uk

\footnotetext{
${ }^{4}$ University of Salford, Academic Enterprise, Salford, M5 4WT, UK

Email: j.a.powell@salford.ac.uk
}
${ }^{5}$ University of Salford, Community Finance Solutions, ESPaCH, Room 214, Crescent House, Salford, M5 4WT, UK
Email: j.e.powell@salford.ac.uk




\title{
Defects Liability Management by Design
}

\begin{abstract}
This paper reports on the findings of a research project that used Action Learning to empower small and medium-sized construction companies to define the agenda for performance improvement and take a leading role in the process of industry change. Whilst achievement of zero defects was an ultimate aim, smaller construction firms identified the shorter-term need to deal effectively with defects during the post-construction phase. Project activities explored problems and identified ways of improving the management of the defects liability period. Proposed solutions ranged from simple modifications to management procedures, through innovative methods of working with tenants to more fundamental changes in design and construction processes. Construction firms and housing associations recognised the importance of working together to improve procedures. The authors conclude that small and medium-sized construction firms are able to address performance issues in practical ways and have a potentially valuable role to play in promoting industry improvement. This paper contributes to a small body of literature investigating the value of Action Learning to construction companies, including small and medium enterprises.
\end{abstract}

Key words: Action Learning, Construction, Defects, Partnership, Quality, SMEs.

Davey, C L, McDonald, J, Lowe, D, Duff, R, Powell, J A and Powell, J E (2006) Defects liability management by design. Building Research and Information, 34(2), 145-153, eScholarID:1a5083 | DOI:10.1080/09613210500492991 


\section{Introduction}

The construction industry has been under pressure from the Construction Industry Task Force, chaired by Sir John Egan (1998), to reduce the number of defects in projects by 20 per cent and to generally improve the quality of service offered to its clients. Quality means not only zero defects, but right first time, delivery on time and to budget, innovating for the benefit of the client and stripping out waste, whether it be in design, materials or construction on site. The Task Force argued that the goal of zero defects was achievable within five years. Indeed, some UK and US construction firms regularly achieve zero defects on handover.

The Task Force states that changes within the construction sector should be brought about through partnering style arrangements (Egan, 1998). Partnering is defined by the Reading Construction Forum (1995) in the Construction Industry Board's (1997) 'Partnering in the Team'as:

"a management approach used by two or more organisations to achieve specific business objectives by maximising the effectiveness of both parties. The approach is based upon mutual objectives, an agreed method of problem resolution, and an active search for continuous measurable improvements" (p. 3).

It is proposed that the social housing sector should take a leading role in establishing partnerships and promoting performance improvement (Egan, 1998), due to its use of public sector funds. Housing associations are the dominant providers of housing in the UK social housing sector, starting schemes (both new build and rehabilitation) worth around $£ 2$ billion for approximately 30,000 homes in 1998/99 (Lunney, 1997). 
Small and medium-sized enterprises (SMEs) are a major group within the construction industry-the European Union (2005) defines an SME as an independent company with fewer than 250 employees, and either an annual turnover not exceeding $€ 40$ million, or a balance sheet not exceeding $€ 27$ million. Unlike clients or large construction companies, SMEs are rarely considered as the instigators of industry improvement programmes (Davey et al., 1999a; 2001; Powell, 1998). By using Action Learning to identify issues and drive project activities, this research was able to develop methods of promoting industry improvement that reflected the priorities of SMEs. In so doing, this research shows how SMEs can be empowered to lead performance improvement within the construction industry (Davey et al., 2001; Powell, 1998).

This paper contributes to a growing number of articles demonstrating the value of Action Learning to construction companies, housing associations (Cooper et al., 1999; Davey et al., 1998b; Davey et al., 1999b; Davey et al., 2002; Davey et al., 2004; Powell, 1998, 2001; Somerville et al., 2002), tenants groups (Lemos and Pedlar, 1999) and organisations wishing to link with community representatives (Carson, 1997). It also contributes to a wider body of literature on 'Action Learning Practice,' comprising cases, reviews and research, and other published articles documenting the preparation, design, implementation and evaluation of Action Learning (Mumford, 1985; Smith and O’Neil, 2003a, b).

\section{Background}


Originated by Reg Revans in the 1940s (Smith and O’Neil, 2003a), Action Learning involves a small group of people — known as a set-coming together to discuss real work-related problems and helping each other come up with solutions (Powell, 1998). Set members commit to giving the issues at hand due consideration-thinking about the problem, questioning, considering methods of resolving issues and reflecting on actions. There is no pre-set objective. Consequently, set members are freely empowered to identify their own issues and priorities (Willis, 2004).

Set members join on a voluntary basis, retain ownership of problems, adopt a questioning approach, accept different view-points and reflect on lessons learnt. There is structure to the set meetings, even though there is no agenda (O'Hara et al., 2004). The members focus on each individual's problem in turn, with the time shared fairly equally between participants. The process of inquiry and self-organisation help generate trust, commitment, engagement and learning (Willis, 2004), with set members gaining strength by becoming 'partners in adversity' (Revans, 1986). Set meetings are only part of the process, however. The other part is the testing of ideas in practice (Smith and O'Neil, 2003a; Willis, 2004).

The sense of discovery that accompanies new insights makes Action Learning very different from management development programmes or future visioning activities (Willis, 2004). However, set members may undergo long periods of 'pondering' or 'mythering,' where little progress is apparently made and questions may be asked about the value of the Action Learning process (Powell, 2001). 
Leading thinkers in Action Learning (Pedlar, 1996; Weinstein, 1995) highlight the value of good facilitation. The facilitator can initiate new behaviours, encourage giving and receiving between participants, make explicit the learning process and steer groups through the various stages of development (Cooper, 1998; O’Hara et al., 2004).

Management training generally emphasises the value of information from accepted authorities (referred to as 'programmed knowledge' by Revans, 1986). However, Revans (1986) emphasises the value of questioning one's own experience by considering:

- Who knows about (understands) the problem being tackled?

- Who cares (genuinely wants something done) about the problem?

- Who can (has enough power to) get something useful done about it?

- What are you trying to do?

- What can't be done (what are the barriers?)?

- What can you do about it?

Revans (1986) also places a strong emphasis on the value of action in the learning process. Mangers, even those who are less senior, are expected to take responsibility for addressing problems, and not simply pass recommendations on to their superiors. In this sense, Action Learning may be described as a process for enabling "learning by experience" or "learning by doing" (Smith and O'Neil, 2003a, p. 63). In terms of change management, Action Learning helps managers understand how to solve problems, and helps generate the motivation, energy and resources to enable individuals to bring about improvements. It enables a group of managers to become a self-changing, democratising and organisation-responsive force that directs its efforts to the common good (Willis, 2004). Action Learning is suited to managers 
wishing to tackle unresolved, complex organisational problems that require sustained effort and energy to address (Edmonstone, 2002). This paper reports on the issues and solutions identified by the participants, when Action Learning was used to help managers from construction SMEs and housing associations improve performance and engage in creative learning.

\section{Methodology}

This research was undertaken by project teams from the University of Manchester (formally UMIST) and the University of Salford. An Action Learning programme for small and medium-sized construction companies was established by the University of Salford (Botham and Vick, 1998). Twenty construction professionals and academics attended an induction event designed to outline the approach and introduce the set adviser (Botham and Vick, 1998; Powell, 1998). Construction SMEs and housing associations in the North West of England had already participated in a project on equality in construction, and were keen to continue working together (Davey et al., 1998a). Consequently, it was relatively easy to form two Action Learning sets, each containing seven people-construction SMEs, housing associations and academics. The aim of the sets was to enable construction SMEs to improve performance and engage in creative learning.

The set meetings took place on a monthly basis. The three-hour long meetings followed a standard Revans format, with individual problems being focused upon in turn. This paper reports on the findings of one of the sets, which ran between 1998 and 2001. This set was facilitated by an advisor for twelve months, but continued to meet regularly for a further year and occasionally thereafter. 
Information about the problems facing construction SMEs and their clients was gathered from participation in the set meetings, and by content analysing minutes of set meetings. The minutes were a verbatim record of discussions in the meeting, and provided insight into the role of Action Learning in setting the agenda for performance improvement. Further information about the process of change was gained from the content analysis of presentations by set members. The presentations were videoed as part of a conference on Action Learning in construction (e.g. Davey and Davies, 1998).

The wider relevance of the issues identified by set members was investigated by the research team from the University of Manchester. Nineteen semi-structured interviews were conducted. These explored the relevance of maintenance defects, communication technology and partnering to other construction companies and clients in the North West of England.

The findings from the set meetings and interviews were used to design three workshops, each attended by around twenty construction professionals. The workshops began with presentations from the project team and outside speakers. The attendees were then divided into groups of six to eight people, and asked to explore problems during the defects liability period and suggest potential solutions. The role of Information and Communication Technologies (ICTs) in improving performance was also considered. The findings were recorded on a flipchart by the participants and fed back to the whole group in a plenary session. Members of the research team observed these discussions, taking detailed notes.

The information from the various set meetings and project activities was analysed to reveal problems and solutions (Davey et al., 1999b), and the findings incorporated into good 
practice guidelines for the management of the defects liability period (Davey et al., 1998b). The guidelines were disseminated to construction companies and clients throughout the UK.

\section{Results}

This section outlines the process of engaging construction SMEs in Action Learning and project activities. It then presents the findings regarding:

- Problems during the defects liability period

- Better management of the defects liability period

- Developing partnerships and sharing good practice

\section{The process of engagement}

The Action Learning process provided participants with an opportunity to raise issues relevant to their own roles and responsibilities. One set member was a contracts manager from Rowlinson Constructions Ltd—a medium-sized construction company based in Cheshire, UK. The company operates in the commercial, industrial, residential and telecommunications sectors of the construction industry and has established long-term partnering relationships with a number of valued clients.

The set meetings encouraged the contracts manager to address a problem of concern to him, namely the management of the defects liability period. His interest in this issue arose, in part, from his firm's participation in a partnering arrangement with a housing association. The contracts manager believed that improved procedures were key to reducing defects and working successfully with clients in the shorter term, as he explains: 
"The emphasis within the industry is to implement the main points summarised in the Egan Report. Through the use of performance indicators, one can monitor improvements year on year. Obviously zero defects are our ultimate aim, but, until the industry reaches this position, it is important that organisations have procedures in place to respond quickly and effectively to matters which can ultimately affect client/contractor relationships" (contracts manager, Rowlinson Constructions Ltd).

The contracts manager produced a twenty-page report, called "Action Learning for Managers: Maintenance Defects Period" (McDonald, 1998), which was discussed during set meetings. Outside of meetings, new practices were implemented and the progress of this fed back to the set. For example, the manager put the topic of defects on the agenda for precontracts meetings and ensured that, wherever possible, outstanding repairs were made on the date of handover.

The set meetings provided new insight into issues of concern to construction SMEs. Moreover, the response of other participants suggested that the management of the defects liability period would be of interest to a wider audience of housing professionals (Davey et al., 1998b). It was also apparent that the contents of the report on maintenance defects would make excellent material for discussions during workshops and could, ultimately, be developed into good practice guidelines. The possibility of focusing on maintenance defects in workshops was raised with set members. The contracts manager and his director agreed 
that the report could be used as the basis of a series of Building Partnerships workshops being planned by the University of Manchester research team. Original plans to address issues highlighted in the previous project, such as 'Best Value' and 'Local Labour', were put on hold (Davey et al., 1998a).

The interviews with construction companies and their clients confirmed the need for improved procedures for managing the maintenance defects. Consequently, with the help of set members and the advisor, the project team designed workshops - two on the management of maintenance defects and one on Information and communication technologies (ICTs). Attracting participants to the workshops proved relatively easy, as the topic was of interest to housing associations and their contractors. Set members also supported project activities by providing industry contacts.

\section{Problems during the defects liability period}

The workshops revealed widespread concern amongst the social housing sector about the number of defects in buildings at handover, as well as the management of defects during the liability period. The cost to housing associations for dealing with defects was estimated at between $£ 50,000$ and $£ 120,000$ per annum, depending upon the size of the association. Construction managers were unhappy about being expected to deal with faults outside of their responsibility caused by factors such as lack of tenant knowledge and routine wear and tear. They wanted to reduce defects because dealing with defects was diminishing profits, which were already dangerously low.

Davey, C L, McDonald, J, Lowe, D, Duff, R, Powell, J A and Powell, J E (2006) Defects liability management by design. Building Research and Information, 34(2), 145-153, eScholarID:1a5083 | DOI:10.1080/09613210500492991 
Defects on handover were attributed to short project time-scales, non-standard designs, insufficient detail in the specification and lack of communication, arising from poor record keeping and the dispersed, casualised nature of the workforce. Poor quality service from construction firms during the defects liability period was attributed, in part, to the fact that, once off-site, firms moved on to new contracts, which often took priority.

Some housing associations further contributed to the difficulties by passing reported faults on to the contractors, without determining their cause, and failing to monitor repair progress. Poor quality persisted because construction firms were excluded from some of the key phases of projects. It was also felt that contractors were not rewarded by clients for providing a quality service or product, only for submitting the lowest bid during the tender stage.

\section{Better management of the defects liability period}

The Action Learning set meetings, workshops and interviews generated a wide range of actions that could be taken by contractors, consultants and clients to reduce defects and improve the management of the defects liability period. Some solutions were fairly easy to implement. These included:

- Putting defects on the agenda at the pre-contract meeting - The early agreement of dates for handover and procedures for managing defects reduces disagreement later on, and increases the likelihood of the project being completed on time.

- Combining repairs and inspections - This prevents contractors from having to arrange for trades people to return to properties to undertake repairs and enables them to provide better service for both clients and tenants. 
- Getting tenants to sign a form saying that repairs have been completed to their satisfaction - This presents a professional image, and the form can be returned to the client to show that work has been completed. By providing a space for information about the cause of the fault, clients and contractors can also monitor and, potentially, improve quality.

- Confirming messages in writing - This reduces the likelihood of a breakdown in communication between construction companies and their clients.

Some methods of improving the management of maintenance defects were more innovative, although often more difficult to implement. These included:

- DIY courses for tenants - DIY training not only reduces the number of unnecessary calls from tenants, it would also provide added value in the form of increased confidence, enjoyment and potentially job opportunities for tenants.

- Setting up a tenants' helpline - This enables housing associations to filter calls from tenants reporting repairs and, where appropriate, provide practical advice about the use of household appliances. Diagnostic manuals, computerised or otherwise, can aid this process.

- Providing tenants with an information pack - This would provide information about appliances and a summary of common faults and repairs, thus helping tenants operate appliances and deal effectively with any problems.

Other solutions proposed by delegates were designed to reduce the overall number of defects and tended to relate to the entire construction process. These included:

- Using standard designs and components.

- Specifying permanent ventilation systems, where design permits.

- Implementing quality control systems, perhaps using IT. 
- Increasing integration between the different groups involved in the construction processThis can be achieved by having maintenance managers from the client organisation attend site meetings.

The industry identified mechanisms for improving performance. Delegates suggested that technology had a significant role to play in the management of maintenance-type problems. In particular, construction professionals were interested in developing computerised manuals and drawings, which can easily be updated. They were also keen to make better use of maintenance software packages to programme maintenance and calculate building life-cycle costs. In addition, technology, such as video-telephone equipment, was considered useful for improving communication between clients, consultants and contractors, as well as reducing travelling time and costs.

Delegates believed that partnering relationships between contractors, clients, suppliers and manufacturers would create a more integrated workforce and provide benefits for the clients in terms of project costs, outcomes and service, especially during the post-construction phase. One participant said that:

"Partnering means discussing the site layout, subcontractors and suppliers... We want the opportunity to negotiate on what the client wants to achieve. We don't want to be given a fixed project with a fixed price. If they bring this to the table, it's too late. Where is the innovation?" (marketing manager, mediums-sized construction company). 
It became apparent that maintenance managers from both client and contracting organisations had much to contribute to performance improvements, although their views had rarely been sought in the past. Exclusion of key individuals resulted partly from their being assigned different roles and responsibilities during the construction process, but also from lack of incentive for people working in construction to improve organisational performance.

The industry identified potential financial benefits from improving the management of the defects liability period. The director of a construction firm estimated that it cost a minimum of $£ 50$ for an operative to attend to a defect and that reducing defects would save money, as well as reduce the disruption caused by an operative having to return to a previous job. In addition, managers from client organisations pay attention to the number of defects on handover and the quality of after-sales service provided by contractors. While they may not have exact performance figures to hand, they report being able to differentiate between contractors who provide a quality service and those who do not. Even though contracts were awarded on the basis of lowest tender price due to the use of Compulsory Competitive Tendering during the 1990s, business opportunities — tendered or negotiated-were more likely to be offered to contractors with a reputation for delivering a quality service, especially during the post-construction phase. Service quality became even more important to clients considering partnering relationships, especially over the long-term.

Housing associations confirmed that, although construction firms that delivered a quality product and service benefit the client over the longer term, they were not necessarily chosen 
by the client due to Compulsory Competitive Tendering. Housing associations recognised the shortcomings of their price-based procurement procedures, but felt compelled during the 1990s to continue with existing practices for fear of criticism from the Housing Association Regulator, as well as doubting the benefits of alternative methods of procurement. A development director, for instance, said:

"Compulsory competitive tendering may not be the best system, but any other methods make us vulnerable to accusations of impropriety or unfairness. It is also very difficult to measure factors other than price" (development director, housing association).

It was recognised, however, that defects and delay in handover cost the housing associations money, and put them at risk of complaints from tenants and punitive action from the Housing Association Regulator.

\section{Developing partnerships and sharing good practice}

Building Partnerships workshops encouraged participation, collaboration and enthusiasm amongst many of the participants. Judging by the feedback from workshops, the project was considered successful by the participants quite simply because it facilitated the development of meaningful relationships, as a director explains:

"The project has managed to prompt, develop and lay the foundation for meaningful liaison, discussion and debate between contractors, clients and other associated parties who need to be working far more together in partnership within the industry" (director, medium-sized construction company). 
Each event identified people keen to give and/or receive assistance-not only with maintenance defects and partnering, but across a range of issues. For example, the project team was asked to help three consultants, three building contractors and two housing associations with partnering, maintenance issues, performance measurement and equal opportunities. The project team's interventions led to changes within some participating organisations and established a number of new alliances. For example, two managers changed communication procedures within the organisation following the maintenance defects workshops and several pilot projects were proposed during the technology workshop. Further support was provided by a local training provider.

In addition, the suggestions generated during the project's activities were recorded, analysed and presented in good practice guidelines. These guidelines were distributed to over 150 construction and housing professionals in the Northwest of England and nationally (Davey et al, 1998b).

\section{Discussion and conclusions}

The findings suggest that some construction SMEs are committed to the Construction Industry Task Force's goal to reduce the number of defects and generally improve the quality of service offered to clients. Between 1997 and 1998, complaints included loose tiles, defective insulation, badly fixed joists, inadequate heating, poor plumbing, shoddy paintwork and inadequate ventilation (Kelly, 1998). Construction SMEs also recognise the value of approaches, such as partnering, proposed by Egan (1998). However, goals like zero defects are difficult for SMEs to achieve over the shorter-term, as they require changes to the 
procurement process and better construction processes. Working towards improvement also requires the involvement of a whole range of staff from the client and contracting organisation, including maintenance managers and staff responsible for briefing tenants or dealing with reported faults. Despite the difficulties, construction SMEs were willing and able to work with industry colleagues and clients to reduce defects and improve procedures for dealing with potential faults. They were also willing to support more innovative solutions, such as DIY courses for tenants.

The study confirmed the perceived value of housing associations and construction SMEs working in partnership to address industry problems (Barlow et al., 1997; Reading Construction Forum, 1995). The results suggest that solutions to industry problems should not simply be 'handed down' to SMEs by representatives from large companies and/or management gurus, who draw on the experiences of other industries and nations. Rather, SMEs should be empowered to take a leading role in defining the agenda and developing solutions (Davey et al., 2001; Powell, 1998). The authors' experience suggests that construction SMEs, many of whom care passionately about the industry, want to be given the opportunity to contribute to the process of industry improvement. SMEs also recognise that, without their participation, any changes to procurement and management practices arising from best practice programmes will reflect the ideas and ultimately the interests of only the large companies (Davey et al., 2004; Nunn et al., 1998).

The advantage of Action Learning was that it empowered a manager within a medium-sized company to focus on a problem of specific concern to him, namely the management of the maintenance defects period. It also helped the manager develop and implement solutions 
appropriate to the company's size and context, rather than implement solutions generated by industry experts or senior management. Construction SMEs were willing to share information in set meetings, due to the development of trust (Davey et al., 2001). Trust arises, in part, from subtle and careful nurturing by a set advisor, as well as from the process of set members working together and overcoming difficulties (Revans, 1986; Powell, 1998; Vince and Martin, 1993). Thus, the findings of this project confirm the value of Action Learning in helping managers from construction SMEs identify performance problems and address these in constructive ways (Cooper et al., 1999; Davey et al., 1999b; Davey et al., 2001; Davey et al., 2002; Powell, 1998, 2001; Somerville et al., 2002).

The project team recognised the value of industry-led change, and was fortunate that the remit of the Building Partnerships project was relatively broad. The academics were therefore able to build upon ideas developed by SMEs, rather than simply address issues previously identified by industry experts.

The involvement of the research team in the Action Learning programme meant that ideas generated by construction SMEs could feed into a project funded by the European Regional Development Fund (ERDF) to run workshops, develop guidance material (Davey et al., 1998b) and offer advice to SMEs. As a result, solutions developed by a small group of organisations were shared with a much wider audience and were of potential benefit to the whole industry. Even though the ERDF-funded project only ran for eight months, the format motivated the researchers and industry participants to continue set meetings, seek out new opportunities for collaboration and ultimately develop research projects together.

Davey, C L, McDonald, J, Lowe, D, Duff, R, Powell, J A and Powell, J E (2006) Defects liability management by design. Building Research and Information, 34(2), 145-153, eScholarID:1a5083 | DOI:10.1080/09613210500492991 
Without being able to feed into an ERDF funded-project, the improvements gained through Action Learning would have been limited to participating construction SMEs and their clients. In other Action Learning sets, construction SMEs have gone on to apply for funding themselves. Failure to secure funding for new projects, however, can result in their being unable to progress ideas and becoming disillusioned with the process of industry change (Davey et al., 2004).

It should be noted that the Action Learning sets built upon an active network of construction and housing professionals established during a previous project (Davey et al., 1998a). Consequently, it did not take long to establish two Action Learning sets. Without access to a network of the contacts interested in collaboration, the formation of a set can take up to year, making it a potentially costly and impractical approach (Davey et al., 2004). In addition, many smaller companies are unable to commit large amount of time and money to such initiatives, without damaging their ability to serve the customer. Consequently, industry improvement programmes involving SMEs require adequate government funding to run activities, and companies should perceive benefits from their involvement.

The participants went on to test their ideas relatively quickly, the period of 'mythering' was therefore fairly short and set members less likely to question their involvement in the set. However, the participants admitted feeling unsure of the process and benefits of Action Learning at the outset. Individuals starting Action Learning programmes would certainly benefit from access to tools and resources designed to communicate the Action Learning process, and perhaps address problems that sometimes occur. 
Individuals participating in Action Learning sets and project activities potentially enhanced their own their reputations and developed business contacts. The contract manager's report on maintenance defects and his involvement in workshops demonstrated the company's commitment to improving the performance of both the company and construction industry in general, and thus potentially offered business benefits. By being involved with the universities and having their support acknowledged, managers gained prestige, knowledge and self-confidence. Indeed, the contracts manager went on to register for a Diploma course in Action Learning at the University of Salford (Botham and Vick, 1998; Davey et al., 1999b). However, some participants clearly benefited more than others, and the set advisor needs to remain alert to signs of disengagement—manifest in the form of reduced participation in meetings, and/or missing sessions.

The interests, motivations and commitment of individuals within Action Learning sets is certainly a key factor in their success - both in terms of processes and outcomes. Participants were genuinely committed to their customers and the industry, as well as concerned about the social and economic region in which they worked. Set members also enjoyed working together, as evidenced by the fact that they continued to hold regular meetings for another twelve months after the programme had officially finished. Barlow et al. (1997) suggest that getting the 'right mix' of people is fundamental to developing successful partnering relationships.

\section{Acknowledgements}


Building Partnerships was funded by the European Regional Development Fund (ERDF) and Manchester Federal School of Business and Management. The Action Learning programme was sponsored by the EPSRC's Construction as a Manufacturing Process Programme-part of its Innovative Manufacturing Initiative. We would like to thank all the people who collaborated with the project, and are particularly grateful to members of the Action Learning set run by the University of Salford.

\section{References}

Barlow, J., Cohen, M, Jashapara, A. and Simpson, Y. (1997) Towards Positive Partnering: Revealing the Realities in the Construction Industry. Bristol: Policy Press.

Botham, D. and Vick, D. (1998) "Revans Centre for Action Learning and Research". Performance Improvement Quarterly, Vol.11, No.2, pp. 5-14.

Carson, L. (1997) "Action Learning Team - Building Bridges within a Local Council”, Journal of Workplace Learning, Vol. 9, No. 5, pp. 148-152

Cooper, I. (1998) "Examining Action Learning and Similar Initiatives". Unpublished report prepared by Eclipse Consultants on behalf of the University of Salford: Salford

Cooper, I., Powell, J.A. and Powell, J.E. (1999) Action Learning and Innovation in Construction: Case Study of the Salford SETs. Report of DoE Partnering in Technology (PIT) project funded under EPSRC's IMI CMP Initiative. The University of Salford: Salford.

Davey, C.L. and Davies, P. (1998) “Action Learning in Construction”. Presentation at the Action Learning for Innovation in Construction Conference, University of Salford, 30th November-1st December.

Davey, C., Davidson, M., Gale, A., Hopley, A. and Rhys Jones, S. (1998a) "Building Equality in Construction: Good practice guidelines". UMIST Working Papers Series, No. 9901.

Davey, C.L., Lowe, D., and Duff, A.R. (1998b) “The Management of Maintenance Defects: Good Practice Guidelines", UMIST Working Papers Series, No. 9904.

Davey, C.L., Lowe, D., and Duff, A.R. (1999) Harmony and Profit in SMEs: The Possibilities and Limitations of Building Partnerships, in Profitable Partnering in Construction Management (Ed. S.O. Ogunlara) CIB W92 Harmony and Profit Symposium, Chaing Mai, Thailand, January $25^{\text {th }}-28^{\text {th }}$. 
Davey, C.L., Lowe, D., and Duff, R. (2001) "Generating Opportunities for SMEs to Develop Partnerships and Improve Performance". Building Research and Information Vol. 29, No. 1, pp1-11.

Davey, C.L. Powell, J.A., J.E. Powell and Cooper, I. (2004) "Innovation, Construction SMEs and Action Learning, Engineering, Construction and Architectural Management, Vol. 11, No.4., pp. 230-237.

Davey, C.L. Powell, J.A., J.E. Powell and Cooper, I. (2002) "Action Learning in a MediumSized Construction Company". Building, Research and Information, Vol. 30, No.1, pp. 5-15.

Davey, C.L. Powell, J.E. and Powell, J.A. (1999) “Action Learning Case Studies,” Funded under EPSRC, EU ADAPT Programme, CIOB and George and Harding. The University of Salford: Salford.

Edmonstone, J. (2002) "Problems and Projects in Action Learning," Industrial and Commercial Training, Vol. 34, No. 7, pp. 287-289.

Egan, Sir John (1998) "Rethinking Construction: The report of the Construction Task Force”. The Stationary Office: London

European Union (2005) “Glossar der Innovationsbegriff”. Innovation Relay Centre. Northern Germany. www.irc-norddeutschland.de/en/info/glossar.html

Kelly, R. (1998) “Complaints Build Over Defects in New Homes”, The Times, News Section, Monday $25^{\text {th }}$ May, p. 9.

Lemos, G. and Pedlar, M. (1999) “Interior Redesign”. Inside Housing, 22 ${ }^{\text {nd }}$ January, pp. 2223.

Lunney, J (1997) Housing Associations in the lead for change. Building Equality in Construction: the Business Case. Seminar organised by UMIST, Building Positive Action and Rhys Jones Consultants, UMIST Conference Centre. 23rd April.

McDonald, J (1998) Action Learning for Managers: Maintenance Defects Period. Report for Action Learning Set. Rowlinson Constructions Limited: Poynton, Cheshire.

Mumford, A. (1985) “A Review of Action Learning," Management Bibliographies and Reviews, Vol.11, No.2, pp. 3-19.

Nunn, D., Reynolds, P. and Ridout, G. (1998) "They Know What's Best for You". Contract Journal, $22^{\text {nd }}$ July, pp. 12-14.

O'Hara, S., Bourner, T. and Webber, T. (2004) "The Practice of Self-Managed Action Learning," Action Learning Research and Practice, Vol. 1, No. 1., pp. 11-27.

Pedlar, M. (1996) Action Learning for Managers. Lemos and Crane: London.

Powell, J.A. (2001) "Action Learning for Construction: A Case Study", in Problems of Participation and Connections Ed. G De Zeuuw and V Martrl, Lincoln Institute Press.

Powell, J.A (1998) Promoting Innovation and Productivity in Construction SMEs (The PIRIC Project): Action Learning for Innovation in Construction. A DoE 'Partners in 
Technology' Project funded under EPSRC's IMI CMP Initiative. The University of Salford: Salford.

Reading Construction Forum (1995) Trusting the Team: the Best Practice Guide to Partnering in Construction, Centre for Strategic Studies in Construction, Reading University, cited in: Construction Industry Board, Partnering in the Team, Thomas Telford: London.

Revans, R. (1986) Action Learning Returns Home. University of Manchester Institute for Development Policy and Management: Manchester.

Smith, P.A.C and O’Neil, J. (2003) “A Review of Action Learning Literature 1994-2000: Part 1 - Bibliography and comments, Journal of Workplace Learning, Vol. 15, No. 2, pp. 63-69.

Smith, P.A.C and O’Neil, J. (2003) “A Review of Action Learning Literature 1994-2000: Part 2 - Signposts into the Literature, Journal of Workplace Learning, Vol. 15, No. 4, pp. 154-166.

Somerville, P. Davey, C.L., Sodhi, D., Steele, A., Gale, A.W., Davidson, M.J. and RhysJones, S. (2002) "Building Equality in Construction Volume II. Good Practice Guidelines for Race and Gender Equality for Building Contractors and Housing Associations”. UMIST Working Paper Series, No. 0201.

Vince, R. and Martin, L. (1993) "Inside Action Learning: An Exploration of the Psychology and Politics of the Action Learning Model". Management Education and Development, Vol. 24, Part 3, pp. 205-215.

Weinstein, K. (1995) Action Learning: A Journey in Discovery and Development. HarperCollins: London.

Willis, V.J. (2004) 'Inspecting Cases Against Revans' 'Gold Standard' of Action Learning," Action Learning Research and Practice, Vol. 1, No. 1., pp. 11-27.

Defects liability final.doc/articles

Davey, C L, McDonald, J, Lowe, D, Duff, R, Powell, J A and Powell, J E (2006) Defects liability management by design. Building Research and Information, 34(2), 145-153, eScholarID:1a5083 | DOI:10.1080/09613210500492991 